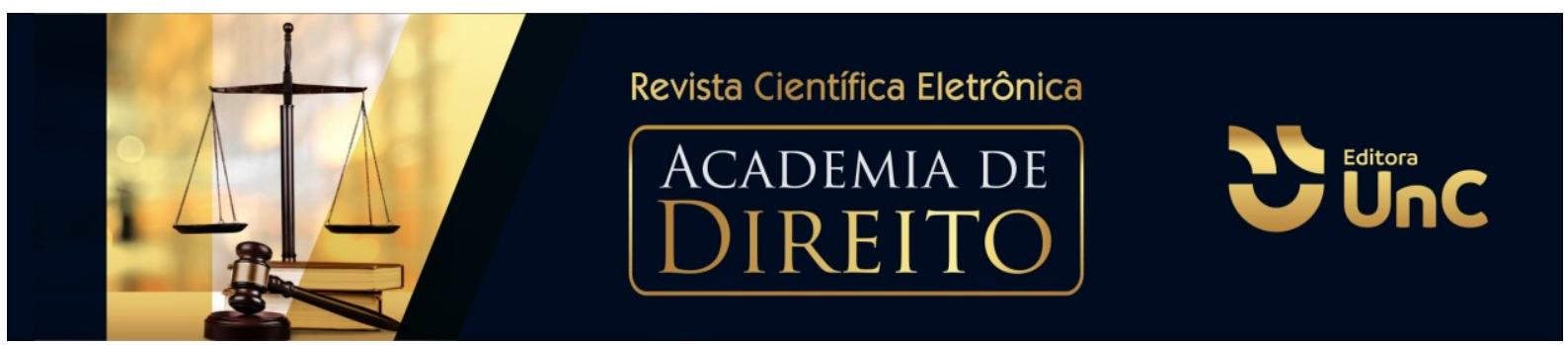

\title{
A FRAGILIDADE DO RECONHECIMENTO DE PESSOAS COMO MEIO DE PROVA NO PROCESSO PENAL BRASILEIRO
}

\section{THE FRAGILITY OF PERSONAL RECOGNITION AS A PROOF IN THE BRAZILIAN CRIMINAL PROCESS}

\author{
Gabrielle Vailate ${ }^{1}$ \\ Willian Vailate ${ }^{2}$
}

\begin{abstract}
RESUMO
O reconhecimento de pessoas corresponde a um dos meios de provas que se encontram disciplinados no Título VII do Código de Processo Penal Brasileiro, consistindo no ato em que uma pessoa afirma como certa a identidade de outra pessoa. Discute-se muito entre os operadores do Direito, especialmente no âmbito penal, se o método utilizado para o reconhecimento de pessoas no processo penal brasileiro pode ser considerado um meio de prova seguro. O presente artigo tem como objetivo investigar a fragilidade do reconhecimento de pessoas como meio de prova no processo penal brasileiro, evidenciando seu elevado grau de falibilidade. Através de pesquisa bibliográfica, embasada no método dedutivo, constatou-se que o reconhecimento de pessoas apresenta-se como uma prova com baixo nível de confiabilidade, tendo em vista os diversos problemas que o cercam, dentre os quais a forma com que é conduzido, as falsas memórias e os falsos reconhecimentos. Assim, pode-se concluir que o reconhecimento de pessoas não é uma ferramenta comprobatória segura de autoria delitiva, mostrando-se necessária uma reforma legislativa que traga maior segurança ao referido instituto.
\end{abstract}

Palavras-Chave: Provas. Valoração. Reconhecimento de Pessoas. Falibilidade.

\footnotetext{
${ }^{1}$ Graduanda em Direito, Universidade do Contestado. Campus Canoinhas. Santa Catarina. Brasil. Email: vailategabrielle@gmail.com.

${ }^{2}$ Especialista Lato Sensu em Direito Civil e Direito Processual Civil pela Faculdade Verbo Educacional. Especialista Lato Sensu em Direito Constitucional pela Universidade Estácio de Sá. Bacharel em Direito pela Universidade do Contestado (UnC). Advogado inscrito nos quadros da Ordem dos Advogados do Brasil do Estado de Santa Catarina. Membro efetivo da Comissão OAB Vai à Escola da Ordem dos Advogados do Brasil (OAB), Subseção de Canoinhas/SC (triênio 2019/2021). Professor de Graduação em Direito da Universidade do Contestado (UnC). Santa Catarina. Brasil. E-mail: willian@vailateadvocacia.com.br.
} 


\begin{abstract}
The recognition of persons corresponds to one of the means of evidence that are disciplined in Title VII of the Brazilian Penal Procedure Code, consisting of the act in which a person affirms the identity of another person. There is a great deal of debate among legal practitioners, especially in the criminal sphere, whether the method used for the recognition of persons in the Brazilian criminal process can be considered a safe means of proof. This article aims to investigate the fragility of the recognition of people as a means of proof in the Brazilian criminal process, highlighting its high degree of fallibility. Through bibliographic research, based on the deductive method, it was found that the recognition of people presents itself as a proof with a low level of reliability, in view of the various problems that surround it, among which the way it is conducted, false memories and false recognitions. Therefore, it can be concluded that the recognition of persons is not a safe mean of proof for criminal authorship, what it shows is necessary a legislative reform that brings greater security to the referred institute.
\end{abstract}

Keywords: Proofs. Valuation. People Recognition. Fallibility.

\title{
1 INTRODUÇÃO
}

O Código de Processo Penal Brasileiro, em seu Título VII, dispõe sobre as provas no processo penal. As provas são os meios pelo qual o juiz formará sua convicção, visando alcançar a verdade substancial.

Os artigos 155 a 250 do Código de Processo Penal Brasileiro descrevem os meios de provas que podem ser produzidos no decorrer da investigação e instrução criminal, com o intuito de verificar se há elementos suficientes de autoria e materialidade.

Salienta-se, ainda, que em razão do princípio do devido processo legal, é vedado ao magistrado, na hora de proferir a sentença, embasar sua convicção apenas com provas produzidas na fase policial, afinal, nesta fase processual o direito ao contraditório não é realizado de forma plena, sendo, portanto, imprescindível as provas também colhidas no decorrer da instrução criminal.

Estão dispostos como meios de prova no Código de Processo Penal Brasileiro: o exame de corpo de delito, a cadeia de custódia e perícias em geral (artigos 158 a 184), o interrogatório do acusado (artigos 185 a 196), a confissão (artigos 197 a 200), a oitiva do ofendido (artigo 201), as testemunhas (artigos 202 a 225), o 
reconhecimento de pessoas e coisas (artigos 226 a 228), a acareação (artigos 229 e 230), os documentos (artigos 231 a 238), os indícios (artigo 239) e por fim, a busca e apreensão (artigos 240 a 250).

Destes meios de prova tipificados pelo diploma processual, aflige grande parte dos doutrinadores do âmbito penal brasileiro, bem como dos operadores do Direito, o reconhecimento de pessoas, isto porque, referido meio de prova se mostra frágil em sua condução, ferindo, por vezes, a liberdade do indivíduo.

Diante disso, o presente artigo buscará responder ao seguinte problema: o método utilizado para o reconhecimento de pessoas no processo penal brasileiro pode ser considerado um meio de prova seguro?

Para tanto, através de pesquisa bibliográfica apoiada no método dedutivo, se buscará, primeiramente, discorrer sobre a evolução dos sistemas processuais, bem como sobre a base principiológica das provas. Na sequência, realizar-se-á uma análise acerca dos meios de prova disciplinados pelo Código de Processo Penal, e sua valoração. Por fim, se buscará entender como é realizado o reconhecimento de pessoas no processo penal brasileiro, demonstrando sua fragilidade como meio de prova.

\section{SISTEMAS PROCESSUAIS E PRINCÍPIOS GERAIS DAS PROVAS Erro!} Indicador não definido.

\subsection{EVOLUÇÃO DOS SISTEMAS PROCESSUAIS}

Conforme leciona Lopes Junior (2019), ao longo dos séculos a estrutura do processo penal acabou sofrendo alterações, as quais ocorreram em razão do predomínio da ideologia libertária ou punitiva, funcionando como uma espécie de termômetro dos elementos autoritários ou democráticos da Constituição de um país.

A doutrina, de acordo com Avena (2017), costuma dividir a estrutura do processo penal em três sistemas, os quais são denominados de sistema processual acusatório, sistema processual inquisitório e sistema processual misto.

Em uma linha cronológica, tem-se que até meados do século XII imperou o sistema acusatório, o qual foi sendo substituído gradativamente para o sistema inquisitório, que, por sua vez, vigorou até o final do século XVIII, embora, em alguns 
países, tenha predominado até parte do século XIX. Ocorre que, a partir do século XIX começaram a surgir movimentos sociais e políticos que caminharam para um sistema misto, isto é, um processo com características tanto do sistema acusatório quanto do inquisitório (LOPES JUNIOR, 2019).

O sistema processual acusatório prevaleceu por quase toda a antiguidade romana e grega, como também pela Idade Média, sob o domínio do direito germânico, entrando em declínio a partir do século XIII, quando passa a prevalecer o sistema processual inquisitório (LIMA, 2019).

Pacelli (2020) leciona que, de maneira geral, a doutrina separa o sistema acusatório do processo inquisitório em razão da titularidade atribuída ao órgão da acusação. No sistema processual acusatório verifica-se a atribuição das funções de acusar e julgar a diferentes órgãos, ou seja, o órgão que acusa não poderá exercer o papel de julgador, a fim de se manter a imparcialidade no julgamento do processo.

Majoritariamente, a doutrina entende que vige no direito pátrio o sistema processual acusatório, uma vez que foi acolhido pela Constituição da República Federativa do Brasil, sendo confiada privativamente ao Ministério Público a função de acusar, com exceção dos casos em que a ação penal é privada. Todavia, este não é um sistema puro, eis que apresenta resquícios do sistema inquisitório, razão pela qual, se torna um sistema processual misto (RANGEL, 2015).

Contrariamente ao sistema acusatório, a principal característica do sistema inquisitório é a concentração dos poderes de julgar e acusar na mesma figura, ou seja, não há imparcialidade. O sistema processual inquisitório caracteriza-se pela prevalência do procedimento escrito, com ausência de debates orais, o procedimento é sigiloso, a confissão do acusado é considerada a prova mais importante, os julgadores não estão sujeitos à recusa, não há contraditório e a defesa é apenas decorativa (NUCCI, 2020).

A igreja foi uma das primeiras a adotar o processo inquisitório, por volta do século XIII, a fim de combater as infrações penais cometidas por indivíduos que iam contra os dogmas pregados pela igreja, ou por aqueles que não os professavam, conhecidos como hereges. Após a adoção deste sistema pela igreja, não demorou muito para que a Europa passasse a utilizá-lo nos processos civis (ROCHA, 1999).

Conforme leciona Lima (2019), a confissão do acusado para o sistema processual inquisitório era considerada a principal prova, por esta razão havia a 
possibilidade de tortura, uma vez que o acusado era mero objeto do processo, não sendo considerado um sujeito de direitos. Assim, na busca da verdade material se adotavam métodos torturantes para se chegar a confissão do acusado.

Nesse sentido, Brito, Fabretti e Lima (2019, p. 4) referem que: "Em tal sistema, as figuras do juiz e do acusador confundem-se e não há limites para os métodos utilizados para a obtenção da rainha das provas: a confissão".

O sistema misto surgiu com o Código de Processo Penal francês, em 1808, caracterizando-se pela junção dos sistemas acusatório e inquisitório, sendo dividido em duas fases. A primeira fase é chamada de inquisitiva, pois corresponde a uma fase preliminar, na qual o procedimento é escrito, sigiloso e não há contraditório. Já a segunda fase seria acusatória, na qual se garante ao acusado todos os direitos constitucionais (BONFIM, 2019).

Leciona Rangel (2015) que, o sistema misto possui viés do sistema acusatório privado de Roma e também do sistema inquisitivo desenvolvido a partir da formação dos Estados nacionais sob o regime da monarquia absolutista, bem como do Direito Canônico. Através dele se buscou solucionar a impunidade que reinava no sistema acusatório, e a imparcialidade que imperava no sistema inquisitório.

Para Nucci (2020), no Brasil vigora o sistema misto, mesmo quando muitos afirmam que a Constituição da República Federativa do Brasil direciona para um sistema acusatório. Isso porque, a adoção de princípios processuais atinentes ao sistema acusatório não é suficiente para dizer que há um sistema exclusivamente acusatório.

Conforme leciona Lima (2019), quando entrou em vigor o Código de Processo Penal o entendimento era de que o sistema previsto era o chamado processo misto, porém, com o advento da Constituição da República Federativa do Brasil, a qual prevê expressamente a distinção das funções de julgar, acusar e defender, assegurando o direito ao contraditório, ampla defesa, bem como presunção da inocência, se está diante de um sistema processual acusatório. No entanto, como predomina entre os doutrinadores, não há que se falar em um sistema acusatório puro, pois o mesmo possui resquícios do sistema processual inquisitório.

Em que pese a ideia de no Brasil vigorar um sistema processual misto, Lopes Junior (2019) refere que dizer que um sistema é misto é basicamente não dizer nada sobre ele, pois, o ponto principal para se determinar a estrutura do processo penal é 
se verificar o princípio fundante, por isso, entende que o processo penal brasileiro é neoinquisitorial. Isto porque, a mera separação das funções de acusar e julgar não é suficiente para dizer que vigora um sistema acusatório, uma vez que o Código de Processo Penal permite ao magistrado a produção de provas de ofício, distanciandose assim da figura de imparcialidade do juiz, um dos elementos que caracterizam o sistema processual acusatório.

\subsection{A BASE PRINCIPIOLÓGICA DAS PROVAS}

No decorrer dos anos os princípios deixaram de ser fonte secundária e subsidiária do Direito, tornando-se o centro do ordenamento jurídico, eis que consentem uma leitura moral do Direito (BARROSO, 2018).

Lopes Junior (2019) refere que os princípios constitucionais são imprescindíveis à leitura da lei processual penal, tendo em vista que a lei remete a uma racionalidade do final do século $\mathrm{XIX}$ e início do século $\mathrm{XX}$, com traços fascistas e autoritários.

De acordo com Bonfim (2019, p. 91), "No específico âmbito do processo penal, os princípios inerentes a ele devem ser estudados sob a ótica do direito constitucional e do direito processual em íntima relação".

A ligação entre os princípios e as provas está relacionada aos meios de prova e aos meios de obtenção das provas. Os meios de prova seriam os meios pelo qual o juiz tem conhecimento da história do fato delituoso, como exemplo se encontram as provas testemunhais, documentais e periciais. Já os meios de obtenção das provas seriam os instrumentos que permitiram se chegar até determinada prova, como por exemplo, a busca e apreensão e interceptação telefônica (LOPES JUNIOR, 2019).

O processo penal deve se pautar na Constituição da República Federativa do Brasil, onde estão previstos grande parte dos princípios, a fim de que o processo seja sinônimo de garantia às arbitrariedades estatais, bem como tenha como objetivo a efetividade da prestação jurisdicional (TÁVORA; ALENCAR, 2016).

Encontram-se como princípios atrelados aos meios de provas: o princípio da autorresponsabilidade das partes, princípio da audiência contraditória, princípio da aquisição ou comunhão da prova, princípio da oralidade, princípio da concentração, 
princípio da publicidade, princípio do livre convencimento motivado e, por fim, princípio da inadmissibilidade das provas obtidas por meios ilícitos.

O princípio da autorresponsabilidade das partes, está relacionado, como leciona Marcão (2018), com a distribuição do ônus da prova, cabendo a cada parte do processo desincumbir-se deste ônus. Caso não o façam, terão que arcar com as consequências que deste ato ocorreram, sendo as partes, portanto, totalmente responsáveis pelos erros e omissões praticados na atividade probatória, respectivamente.

Em relação ao ônus da prova, ensinam Brito, Frabretti e Lima (2019, p. 167):

\begin{abstract}
Por ônus devemos sempre entender encargo. Não é correto se dizer que existe uma obrigação de provar, pois sempre que utilizamos a palavra obrigação dizemos que de outra parte haverá um direito. Se dizemos que existe uma obrigação de provar, devemos dizer que existe um direito de alguém exigir esta prova, sob algum tipo de sanção. Não é o que acontece com a prova, e por isso devemos falar de faculdade, de encargo, de ônus: caso a parte pretenda se beneficiar do que alega, deverá apresentar algum tipo de prova; se não apresentar, não pode se beneficiar do alegado.
\end{abstract}

O princípio da audiência contraditória, mais conhecido como princípio do contraditório, foi inserido explicitamente na Constiuição da República Federativa do Brasil de 1988, entretanto, nas Constiuições anteriores já aparecia de forma implícita. Acontece que, apenas em 1988 referido princípio fundou-se como direito de proteção à liberdade (TÁVORA; ALENCAR, 2016).

Lopes Junior (2019) refere que, o princípio do contraditório, de início, pode ser considerado como um método de confrontação da prova, bem como da comprovação da verdade, isto porque, funda-se no conflito entre as partes, que são: acusação, que está relacionada aos interesses do Estado, e a defesa, que tem ligação com os interesses do acusado em se livrar das acusações, bem como de ficar imune da aplicação de penas desproporcionais e arbitrárias. Assim, o contraditório se torna indispensável para a existência da estrutura dialética do processo.

Pelo princípio da aquisição ou comunhão da prova, como é mais conhecido, as provas indicadas por uma das partes não podem ser consideradas alheias à outra parte, desta forma, as provas acabam se comunicando e, consequentemente, uma vez admitidas, pertencerão ao julgador, defesa e acusador (ROCHA, 1999). 
Desta forma, como leciona Rangel (2015), o princípio da comunhão da prova é uma consequência lógica dos princípios da igualdade entre as partes e da verdade processual, tendo em vista que, na busca em determinar a verdade histórica nos autos, as partes não renunciam aos meios de prova levados ao processo.

No tocante ao princípio da oralidade, as provas, conforme leciona Avena (2017), como regra geral, devem ser produzidas oralmente e na presença do magistrado, a fim de que a prevalência da palavra falada possibilite ao juiz participar dos atos de obtenção da prova, isto ocorre, por exemplo, no caso da oitiva de testemunhas. O testemunho produzido durante a audiência é mais valioso do que uma mera declaração escrita trazida aos autos, por isso, a oralidade, mais do que um princípio, retrata uma forma de se conduzir o processo.

O princípio da concentração, por sua vez, decorre do princípio da oralidade, que prima que as alegações finais sejam apresentadas ao final da audiência, por isso, este princípio visa que toda a produção de provas ocorra durante a audiência de instrução e julgamento (CAPEZ, 2019).

Quanto ao princípio da publicidade, Nucci (2015) refere que esta é de extrema importância para a transparência e moralidade. Desta forma, no âmbito do Direito, a publicidade visa dar conhecimento à sociedade dos atos judiciais, pois, a justiça é considerada de todos. Ocorre que, em algumas situações, o direito à publicidade dos atos judiciais se depara com outros valores resguardados pelo Estado Democrático de Direito, por isso, o segredo e o sigilo acabam caminhando junto a publicidade.

No que se refere ao princípio do livre convencimento motivado, este relacionase com a ideia de que o magistrado não está comprometido com nenhum critério de valoração da prova, sendo livre na formação de seu convencimento, podendo, inclusive, adotar um único testemunho, por exemplo, para embasar um decreto condenatório, desde que em consonância com as demais provas que dos autos constam, fazendo a sua fundamentação (PACELLI, 2020).

Por fim, com relação ao princípio da inadmissibilidade das provas obtidas por meios ilícitos, no processo penal brasileiro não se admite, em regra, a utilização de provas obtidas através de meios ilícitos, por isso, o magistrado não poderá utilizar de uma prova ilícita para formar sua convicção. É considerada prova ilícita aquela obtida por meio que afronte direta ou indiretamente às garantias tuteladas pela Constituição da República Federativa do Brasil (AVENA, 2017). 


\section{MEIOS DE PROVA E A VALORAÇÃO DAS PROVAS}

\subsection{AS PROVAS DISPOSTAS NO CÓDIGO DE PROCESSO PENAL BRASILEIRO}

Conforme leciona Messias (2001), as provas correspondem aos elementos do processo, sendo responsáveis pelo fornecimento de juízo de certeza moral na aplicação da lei. Dos elementos que compõem o processo penal, pode-se dizer que as provas são as que possuem maior relevância para a construção da justiça.

A ação, no processo penal, tem por finalidade a aplicação de uma sanção ao autor da infração penal e, para que isto ocorra, é necessário demonstrar ao julgador, através dos meios de prova, a verdade do fato tido como criminoso, bem como sua autoria (DEMERCIAN; MALULY, 2014).

Brito, Fabretti e Lima (2019) referem que a função das provas é reconstruir as circunstâncias e o fato, assim, caracterizam-se como instrumento de busca da verdade. Entretanto, ainda que o intuito seja alcançar o mais próximo da realidade, a reconstrução dos fatos nunca será perfeita.

O Código de Processo Penal Brasileiro descreve como meios de prova: o exame de corpo de delito, a cadeia de custódia e perícias em geral (artigos 158 a 184), o interrogatório do acusado (artigos 185 a 196), a confissão (artigos 197 a 200),

a oitiva do ofendido (artigo 201), as testemunhas (artigos 202 a 225), o reconhecimento de pessoas e coisas (artigos 226 a 228), a acareação (artigos 229 e 230), os documentos (artigos 231 a 238), os indícios (artigo 239) e por fim, a busca e apreensão (artigos 240 a 250).

Primeiramente, no tocante à prova pericial, esta corresponde a uma prova técnica e tem como objetivo auxiliar o julgador na certificação de fatos que exigem um conhecimento profissional específico para sua compreensão. Deve, por isso, constituir a principal prova a ser buscada, tendo em vista sua confiabilidade e qualidade (BRITO; FABRETTI; LIMA, 2019).

Confome leciona Pacelli (2020), se uma infração deixa vestígios, a materialidade do delito e a extensão de suas consequências deverão ser objeto de prova pericial, a qual deverá ser realizada diretamente sobre o objeto material do fato criminoso, o corpo de delito, ou, não podendo mais sê-lo, pelo desaparecimento inevitável do vestígio, de modo indireto. 
A cadeia de custódia foi incluída pela Lei n. 13.964/2019, tendo sua definição no artigo 158-A, caput, do Código de Processo Penal Brasileiro, in verbis:

Art. 158-A. Considera-se cadeia de custódia o conjunto de todos os procedimentos utilizados para manter e documentar a história cronológica do vestígio coletado em locais ou em vítimas de crimes, para rastrear sua posse e manuseio a partir de seu reconhecimento até o descarte (BRASIL, 1941).

Segundo Nucci (2020), a lei processual penal aperfeiçoa-se prevendo a cadeia de custódia, a qual se inicia desde a preservação do local do crime, onde o agente público, quando identificar um elemento fundamental para a perícia, deve preservá-lo.

O interrogatório judicial, por sua vez, é o ato que está previsto nos artigos 185 a 196 do Código de Processo Penal Brasileiro, pelo qual o magistrado procede à oitiva do acusado sobre a sua pessoa e também sobre a imputação que lhe é feita, razão pela qual, se diz que o interrogatório se divide em duas partes. A primeira parte consiste em questionamentos sobre a residência, meios de vida ou profissão, local onde exerce a sua atividade, vida pregressa, bem como oportunidades sociais. Já a segunda corresponde aos fatos narrados na exordial acusatória, tendo o acusado a possibilidade, nesta segunda parte, de exercer o direito ao silêncio (LIMA, 2019).

Já a confissão do acusado, como leciona Pacelli (2020, p. 311): “[...] constitui uma das modalidades de prova com maior efeito de convencimento judicial, embora, é claro, não possa ser recebida como valor absoluto".

No tocante ao ofendido, como refere Bonfim (2019), este corresponde ao sujeito passivo da infração penal, eis que é a vítima do fato delituoso. Por isso, para os efeitos legais, a vítima não é comparada às testemunhas, uma vez que, por ser a prejudicada imediata da infração penal, tem interesse na condenação do acusado. Desta forma, embora suas declarações sejam de suma importância para o processo, tendo em vista sua proximidade natural com os fatos apurados, é necessário que suas declarações sejam interpretadas com reserva.

O testemunho, consoante Machado (2014), condiz com a exposição verbal feita perante o magistrado, por aquele que tenha ciência do fato criminoso ou que tenha conhecimento sobre algum ponto relevante sobre o fato que é objeto da acusação. Destarte, o testemunho pode ser prestado por aquele que presenciou os fatos 
diretamente, bem como por aquele que teve conhecimento de alguma circunstância que interessa ao deslinde da questão criminal.

Por seu turno, o reconhecimento de pessoas e coisas é o meio de prova que se encontra disciplinado nos artigos 226 a 228, todos do Código de Processo Penal Brasileiro, caracterizando-se, como leciona Capez (2019), por ser meio de prova eminentemente formal, pelo qual alguém é chamado a verificar e confirmar a identidade de uma pessoa ou coisa que lhe é apresentada, a fim de compará-la com outra que viu no passado.

A acareação encontra previsão nos artigo 229 e 230, ambos do Código de Processo Penal Brasileiro, sendo admitida entre os acusados, entre acusados e testemunhas, entre testemunhas, entre vítimas, entre acusado e vítima e ainda entre testemunha e vítima. Aliás, referido meio de prova pode ser utilizado tanto na fase investigativa quanto na fase judicial, sempre que as declarações divergirem sobre fatos ou circunstâncias relevantes, respeitando-se sempre o direito do imputado não participar do ato. $\mathrm{O}$ ato deve ser realizado em audiência, constando a descrição das perguntas e respostas na ata (LOPES JUNIOR, 2019).

Segundo Lima (2019), o conceito de documento pode ser interpretado de forma estrita ou ampla. A concepção estrita encontra-se na redação do artigo 232, caput, do Código de Processo Penal, segundo a qual, documento é toda peça escrita que condensa graficamente o pensamento de alguém, podendo provar um fato, bem como realizar algum ato que seja dotado de relevância jurídica. Já numa concepção ampla, tem-se que o documento é qualquer objeto representativo de um fato ou ato relevante, no qual pode-se incluir as fotografias, desenhos, filmes, esquemas, figuras digitalizadas, e-mails, entre outras. Entretanto, em ambas as concepções a característica principal é a relevância jurídica.

Messias (2001) refere que os indícios correspondem ao meio de prova que dão a entender a autoria ou a forma de um determinado fato, baseando-se em outros elementos que apontam para uma mesma direção, criando um raciocínio de verossimilhança, ou seja, um raciocínio de probabilidade. Assim, onde maiores e mais convincentes forem os indícios, maior será a chance de acerto desta espécie de prova.

A busca e apreensão, último meio de prova tratado no Título VII do Código de Processo Penal, nos artigos 240 a 250, ao contrário dos demais meios de prova já mencionados, os quais são produzidos, desde o início, em contraditório, segue 
procedimento diverso, em atenção às peculiaridades da medida. Aludido meio de prova, trata-se, por certo, de medida de natureza eminentemente cautelar, a fim de proteger material probatório, coisas, animais e até pessoas, que não estejam ao alcance da justiça (PACELLI, 2020).

\subsection{SISTEMAS DE VALORAÇÃO DAS PROVAS}

Ao longo da história, diversos foram os julgamentos que ocasionaram a morte, mutilação, tortura e até mesmo exílio de pessoas. Julgamentos como os mencionados, caracterizaram-se por uma valoração probatória cujo intuito era causar dor ao outro, no qual o julgador se via no direito de valorar a prova sem convicções fundamentadas (MENDRONI, 2015).

Conforme leciona Avena (2017), no decorrer dos anos, a apreciação da prova passou por fases distintas, conforme as convicções, costumes, conveniência, bem como pelo regime de cada povo. Diante disso, primitivamente, foi adotado o sistema étnico ou também chamado pagão, onde o juiz apreciava as provas de acordo com sua experiência. Posteriormente, começou a ser aplicado o sistema religioso ou também conhecido como ordálio, no qual se invocava um julgamento divino como critério de definição da inocência ou culpa. Entretanto, com a evolução do direito, passou a vigorar o sistema legal, que, com o passar do tempo, foi substituído por um sistema de íntima conviç̧ão e, por fim, por um sistema de livre convencimento motivado.

No chamado sistema de convicção legal ou também conhecido como sistema legal de provas, o legislador previa a priori, através da experiência coletiva acumulada, um sistema de valoração hierarquizada da prova, isto é, estabelecia-se uma tarifa probatória. O valor das provas vinham previamente definidos em lei, sem considerar as particularidades de cada caso, sendo que, a confissão era tida como uma prova absoluta, sobre a qual o depoimento de uma testemunha não tinha valor (LOPES JUNIOR, 2019).

O sistema da íntima convicção corresponde ao sistema que confere ao magistrado total liberdade na formação de seu convencimento, dispensando-o de motivar as razões que o levaram àquela decisão, não possuindo relevância a circunstância de se encontrar ou não a prova nos autos (AVENA, 2017). 
Já o chamado sistema da livre conviccção motivada é uma superação dos dois sistemas citados acima. Conforme leciona Pacelli (2020), neste sistema o juiz tem total liberdade na formação de seu convencimento, sem estar comprometido por qualquer critério de valoração prévia da prova, por esta razão, um único testemunho pode ser levado em consideração pelo magistrado, ainda que este esteja em sentido contrário com dois ou mais testemunhos, contudo, este deve estar em consonância com as demais provas que dos autos constam. Salienta-se, no entanto, que a liberdade de convencimento não dispensa sua fundamentação, isto é, em que pese a liberdade na formação de sua convicção, o julgador deverá declinar as razões que o levaram a optar por tal prova.

\section{DO RECONHECIMENTO DE PESSOAS E DAS CRÍTICAS À SUA CONDUÇÃO}

\subsection{O RECONHECIMENTO DE PESSOAS COMO MEIO DE PROVA NO PROCESSO PENAL BRASILEIRO}

Inicialmente, para que se possa compreender o reconhecimento de pessoas como meio de prova, é preciso definir o que é reconhecimento.

Nesse sentido, de acordo com as palavras de Capez (2019, p. 461), o reconhecimento "É o meio processual de prova, eminentemente formal, pelo qual alguém é chamado para verificar e confirmar a identidade de uma pessoa ou coisa que lhe é apresentada com outra que viu no passado".

O reconhecimento, como leciona Messias (2001), está previsto nos artigos 226 a 228 do Código de Processo Penal, podendo incidir sobre pessoas e coisas. Incidirá sobre pessoas quando houver suspeitas congruentes de que a pessoa a ser reconhecida tenha tido alguma espécie de participação no fato delituoso. Incorrerá sobre objeto ou coisas quando se entender que tal objeto possa ter vínculo com a infração penal.

O artigo 226 do Código de Processo Penal descreve as formalidades que devem ser observadas no procedimento do reconhecimento. Primeiramente, a pessoa que tiver de fazer o reconhecimento será convidada a descrever a pessoa que deve ser reconhecida, a teor do que determina o inciso I do artigo 226 do Código de Processo Penal Brasileiro. 
Esta precaução, segundo Nucci (2020), é de suma importância para que o processo fragmentário da memória se torne conhecido, isto é, para que o magistrado perceba se o reconhecedor tem a mínima fixidez para proceder ao reconhecimento. Isto quer dizer que, se o reconhecedor descrever uma pessoa com dois metros de altura, por exemplo, não poderá, posteriormente, reconhecer como autor do fato delituoso um anão.

Na sequência, a pessoa, cujo reconhecimento se pretender, deve ser colocada ao lado de outras que com ela tiverem qualquer semelhança, se tal for possível, convidando-se quem tiver de fazer o reconhecimento a apontá-la, conforme dispõe o inciso II do artigo 226 do Código de Processo Penal. Por isso, o reconhecedor precisa se valer do processo de comparação, a fim de que possa buscar na sua consciência a imagem efetiva daquele que viu cometer o ilícito (NUCCl, 2020).

No tocante ao reconhecimento realizado na Delegacia de Polícia, referem Brito, Fabretti e Lima (2019) que, se houver receio por parte da pessoa chamada para o reconhecimento de ser influenciada ou intimidada de forma diversa, a autoridade policial providenciará para que o reconhecedor não seja visto. Todavia, em juízo, a lei não faz referida ressalva, o que significa que não se pode esconder a identidade de quem reconhece. Em que pese tal fato, os autores destacam que se tem admitido a proteção da imagem da pessoa também no âmbito judicial, aplicando-se, por analogia, norma do Código de Processo Penal que possibilita que a testemunha que se sentir ameaçada pode prestar o seu depoimento sem a presença do acusado. Por fim, os autores ressaltam que, ao final do procedimento, deve ser lavrado um auto de reconhecimento pormenorizado, o qual é subscrito pela autoridade, pela pessoa chamada para proceder ao reconhecimento e por duas testemunhas presenciais.

Outro ponto importante a ser destacado é que, embora o artigo 226 do Código de Processo Penal Brasileiro descreva as formalidades que devem ser observadas em relação ao reconhecimento, tal dispositivo menciona apenas o reconhecimento feito ao vivo, e não por meio de fotografia (CAPEZ, 2019).

Sobre o tema, Lopes Junior (2019) refere que o reconhecimento do imputado por fotografia é um típico exemplo de forma inadmissível, pois, segundo o mesmo, uma prova rotulada de inominada não pode ser admitida quando na verdade decorre de uma variação ilícita de outro ato estabelecido na lei processual penal, onde as garantias constitucionais não foram observadas. 
Pacelli (2020) menciona que o reconhecimento realizado por fotografias jamais poderá ter valor probatório idêntico ao reconhecimento de pessoas realizado ao vivo, diante das dificuldades notórias de correspondência entre uma fotografia e uma pessoa, devendo ser utilizado apenas em casos excepcionais, quando puder servir como elemento de confirmação das demais provas que constam nos autos.

Ademais, como bem pontua Bonfim (2019), quando se fala no valor probatório do reconhecimento de pessoas, há que se frisar que este é variável, tendo em vista o sistema de valoração adotado pelo sistema penal brasileiro, qual seja, a livre convicção motivada, sistema que permite ao magistrado valorar a prova livremente, desde que fundamente tal decisão. Ocorre que, apesar de o reconhecimento ser tido por muitos como uma importante ferramente para fins de comprovação da autoria do fato delituoso, na verdade, corresponde a uma ferramenta comprobatória passível de gerar sérias injustiças criminais.

\subsection{CRÍTICAS AO RECONHECIMENTO DE PESSOAS E CASOS DE REPERCUSSÃO NA MÍDIA}

Ao realizar-se uma rápida pesquisa através de mecanismos de buscas disponíveis na internet, pode-se facilmente encontrar inúmeras notícias à respeito de casos em que o reconhecimento de pessoas ocasionou a prisão ou até mesmo a condenação de pessoas inocentes, as quais foram identificadas por vítimas ou testemunhas oculares como autoras do crime.

Conforme leciona Messias (2001), nem sempre se pode afirmar com segurança quem tenha sido o autor, coautor ou personagem que interessa a identificar no processo. Tal situação também ocorre com objetos ou coisas que tenham ou possam ter alguma relação com o fato sob investigação. É por isso que, segundo o referido autor, o ato do reconhecimento deve ser revestido da maior seriedade, pois corresponde a uma prova de suma importância no processo penal, contudo, lastimavelmente, na maioria das vezes, é realizado de maneira negligente, com as formalidades relegadas a um plano secundário, gerando dúvidas insanáveis ou até mesmo nulidades, isto quando não ocasiona em erros judiciários.

Lopes Junior (2019) refere que, o reconhecimento de pessoas pode ser sequencial ou simultâneo, no entanto, a forma escolhida pelo Código de Processo 
Penal Brasileiro é o simultâneo, método que, segundo o autor, pode ser perigoso e sugestivo, pois, os que estão entre os possíveis suspeitos do crime são apresentados ao mesmo tempo.

Para Avena (2015) os incisos do artigo 226 do Código de Processo Penal Brasileiro visam afastar a fragilidade que cerca o reconhecimento de pessoas como meio de prova no processo penal, contudo, menciona sobre a necessidade de uma reforma legislativa que traga maior segurança à referido ato.

Como bem pontua Nucci (2020), as regras previstas no artigo 226 do Código de Processo Penal devem ser observadas, eis que não se trata de um procedimento qualquer, por isso, este meio de prova não pode ser realizado conforme a vontade arbitrária da autoridade policial ou do juiz.

Com relação à falibilidade de referido meio de prova, Tourinho Filho (1979, p. 288 apud MESSIAS, 2001, p. 449) refere que: "A ação do tempo, más condições de observação, erros por semelhança, a vontade de se reconhecer; tudo, absolutamente tudo, torna o reconhecimento uma prova altamente precária".

Além da imprescindibilidade da observância às formalidades, há ainda outras questões que cercam o reconhecimento de pessoas, são elas: as falsas memórias e os falsos reconhecimentos, os quais devem ser considerados pelos atores do judiciário ao proceder à valoração da prova (LOPES JUNIOR, 2019).

Neste norte, Lopes (2011, apud BRITO; FABRETTI; LIMA, 2019, p. 203) refere que:

[...] são vários os estudos e pesquisas no campo da Psicologia moderna sobre a capacidade de armazenamento de informações que evidenciam as falhas e erros que podem advir da memória. E quanto ao reconhecimento, a autora entende que o processo psicológico é ainda mais profundo por ser imediata ativação dos complexos mecânicos da memória.

Além disso, como leciona Lopes Junior (2019), em que pese o criminoso nato de Lombroso seja apenas um marco histórico da criminologia, é evidente que ele habita o imaginário de muitos, em especial nos países com profundos contrastes sociais, baixo nível cultural e também com alto índice de violência urbana, como o Brasil. Desta forma, um dos estereótipos mais presentes, segundo diversos autores, é o de lo que es hermoso es bueno, ou seja, um indivíduo com um rosto mais bonito 
e atraente possui, aos olhos da sociedade, mais traços de uma conduta socialmente desejável e aceita, do que um indivíduo "mal-apessoado".

As críticas tecidas pelos doutrinadores sobre as questões que envolvem o reconhecimento de pessoas são facilmente percebidas em notícias sobre os casos de falsos reconhecimentos, também de prisões e até mesmo condenações injustas. Como exemplos, pode-se citar os casos do Maníaco do Anchieta, de Igor Barcelos Ortega, do DJ Leonardo Nascimento e do borracheiro Antônio Cláudio Barbosa de Castro.

De acordo com a reportagem trazida pelo R7 Notícias, em 20 de agosto de 2019, o caso do Maníaco do Anchieta ganhou destaque no ano de 1995, quando o artista plástico Eugênio Fiúza de Queiroz foi reconhecido por nove vítimas como o autor de vários estupros que aconteceram na década de 90 em Belo Horizonte/MG. Eugênio Fiúza foi condenado a 37 anos de prisão e passou 17 anos em cárcere privado, sendo inocentado apenas no ano de 2015. A declaração de inocência ocorreu 2 anos após o verdadeiro Maníaco do Anchieta se entregar à justiça, bem como ser identificado por diversas vítimas, dentre as quais, vítimas que haviam reconhecido Fiúza como autor anteriormente (PAVANELLI, 2019).

Após ter sido finalmente inocentado, Eugênio ajuizou ação de reparação de danos contra o Estado de Minas Gerais, noticiando ter sido preso e condenado por crimes que, efetivamente, não cometeu, sendo que, em sentença proferida pelo juiz Rogerio Santos Araujo Abreu, da $5^{\mathrm{a}}$ Vara da Fazenda Pública e Autarquias da Comarca de Belo Horizonte/MG, em outubro de 2019, nos autos do processo de $\mathrm{n}^{\circ}$ 5054558-63.2016.8.13.0024, o Estado de Minas Gerais foi condenado a pagar a Eugênio indenização no patamar de $\mathrm{R} \$ 2.000 .000,00$ (dois milhões de reais), a título de indenização por dano moral e $\mathrm{R} \$ 1.000 .000,00$ (um milhão de reais) a título de danos existenciais, além do pagamento de danos materiais na forma de pensão vitalícia (BRASIL, 2019).

Oportuno mencionar, ainda, que no caso do Maníaco do Anchieta, Eugênio não foi o único inocente a ser confundido com o verdadeiro autor dos crimes. No ano de 1997, Paulo Antônio da Silva foi condenado a 30 anos de prisão. Porteiro, Paulo também foi reconhecido como autor de um dos casos de abusos que aconteceram na década de 90 na região Centro-Sul de Belo Horizonte/MG, quando uma das vítimas o reconheceu. Paulo passou 5 anos e 7 meses na prisão e outros 11 anos em regime 
domiciliar. Somente no ano de 2013 conseguiu provar sua inocência, quando o verdadeiro autor se entregou (PAVANELLI; RAMOS, 2019).

Os casos acima citados elucidam o fato de que as memórias não podem ser consideradas plenamente confiáveis, especialmente, quanto a eventos traumáticos. Nesse sentido, lecionam Fiorelli e Mangini (2017, p. 88):

\begin{abstract}
Deixar-se dominar pela emoção significa comprometer percepção, atenção, pensamento e memória e abrir espaço para enganos de raciocínio (falsas inferências, conclusões inadequadas), falhas de percepção (fixação em figura inadequada, eliminação de detalhes), lapsos e outros fenômenos psíquicos. As emoções sujeitam o indivíduo a crenças inadequadas, esquemas rígidos de pensamento, pensamentos automáticos, preconceitos, e fazem aflorar mecanismos de defesa que comprometem o desempenho no papel.
\end{abstract}

Outro caso de destaque, conforme reportagem também do R7 Notícias, do dia 30 de julho de 2019, é o de Igor Barcelos Ortega, jovem de 22 anos de idade, condenado a 15 anos e 6 meses de prisão em primeira instância por roubo e tentativa de latrocínio. $O$ jovem permaneceu preso por 2 anos e 8 meses em razão de um reconhecimento supostamente equivocado, sendo que, no momento, aguarda o julgamento do processo em segunda instância a fim de que sejam considerados os indícios que apontam para a sua inocência (DALAPOLA, 2019).

Mais um caso de repercussão nacional envolvendo o reconhecimento de pessoas foi o caso do DJ Leonardo Nascimento, o qual, conforme reportagem do site G1, de 25 de janeiro de 2019, foi preso injustamente pelo latrocínio de Matheus Lessa em um mercadinho da Zona Oeste do Rio de Janeiro. Leonardo Nascimento foi reconhecido por quatro testemunhas, incluindo a mãe da vítima, contudo, posteriormente ao reconhecimento de Leonardo, foi apresentado imagens deste circulando em outra área da cidade no mesmo momento do crime. Tal fato, conforme destaca a advogada de Leonardo na reportagem, evidencia o erro na hora do reconhecimento de pessoas na Delegacia de Polícia, eis que os indivíduos identificados posteriormente como autores do delito possuíam, inclusive, etnia diferente de Leonardo. Neste caso, Leonardo ficou preso por uma semana (SALVIANO, 2019).

Por fim, cabe mencionar o caso do borracheiro Antônio Cláudio Barbosa de Castro, preso e condenado pelo crime de estupro de vulnerável em 2014, após ter sido confundido com o criminoso que ficou conhecido como "maníaco da moto", que 
circulava em uma motocicleta vermelha, ameaçava e abusava de mulheres em ruas de Fortaleza. No caso de Antônio, conforme reportagem publicada pelo site da Folha de São Paulo, no dia 05 de agosto de 2019, chama atenção o fato de que, a principal prova que levou a justiça a condená-lo a 9 anos de prisão foi o reconhecimento feito por uma menina de 11 anos de idade. Antônio ficou preso por quase 5 anos, somente sendo inocentado no final de julho de 2019. O laudo de um vídeo apontando que o possível estuprador era mais alto que Antônio foi a principal prova apresentada pela defesa no julgamento para a revisão da sentença que o havia condenado. Além disso, o fato de crimes com as mesmas características terem continuado a ocorrer após a prisão de Antônio também colaboraram no novo julgamento (RIZZO, 2019).

A liberdade, como se sabe, é um dos direitos fundamentais, senão o mais importante, dentre os que estão insculpidos no caput do artigo $5^{\circ}$ da Constituição da República Federativa do Brasil. Ocorre que, este direito fundamental, conforme demonstrado através dos casos acima mencionados, por vezes, é colocado em risco com a realização do reconhecimento de pessoas, uma vez que, este meio de prova depende da memória humana, a qual está sujeita às falsas memórias.

De acordo com Messias (2001), a autoridade que preside o reconhecimento deve transmitir ao reconhecedor serenidade e calma, a fim de evitar um reconhecimento que se processe com precipitação. Na lição de Fiorelli e Mangini (2017, p. 90), "Uma pergunta, efetivamente, pode produzir falsas associações na memória; dependendo da formulação, sugere um fato que leva a outro e assim por diante, afastando-se do real dos acontecimentos ou aproximando-se deles".

Por isso, a autoridade responsável pela condução do reconhecimento de pessoas deve evitar perguntas ou afirmações tendenciosas, tais como, o "responsável já está preso", "já prendemos o criminoso", pois, tal comportamento pode levar o reconhecedor a identificar uma pessoa que pode não ser a verdadeira responsável pelo delito (MESSIAS, 2001).

\section{CONSIDERAÇÕES FINAIS}

Conforme pode-se verificar, no decorrer dos séculos o processo penal apresentou-se em diferentes modelos, os quais foram evoluindo de acordo as 
ideologias que imperavam à época. Estes sistemas foram denominados de sistema processual acusatório, sistema processual inquisitório e sistema processual misto.

No Brasil, embora a Constituição da República Federativa do Brasil tenha adotado no artigo 129, inciso I, o sistema processual acusatório, levando-se em conta o que foi observado, percebe-se que não se trata de um sistema "puro", pois, o inquérito policial reveste-se de características do sistema inquisitivo, enquanto a fase da acusação, isto é, da instrução e julgamento, apresenta atributos do sistema acusatório, razão pela qual, parte da doutrina defende que o Brasil possui um sistema misto.

Já no tocante às provas, constatou-se que os princípios são de suma importância para a leitura do processo penal, destacando-se os princípios da autorresponsabilidade das partes, da audiência contraditória, da aquisição ou comunhão da prova, da oralidade, da concentração, da publicidade, do livre convencimento motivado e da inadmissibilidade das provas obtidas por meios ilícitos.

Bem assim, pode-se verificar, ainda, que o processo penal brasileiro, quanto à valoração da prova, adotou o sistema da livre conviccção motivada, de modo que, embora o juiz tenha total liberdade na formação de seu convencimento, não estando vinculado a qualquer critério de valoração prévia da prova, não está dispensado de fundamentar a escolha de tal prova.

Ademais, em vista dos aspectos apresentados, percebe-se que, de todos os meios de provas previstos no Título VII do Código de Processo Penal Brasileiro, o reconhecimento de pessoas e coisas, cuja disciplina encontra-se nos artigos 226 a 228 do referido diploma legal, é o que causa mais temor na maioria dos doutrinadores penalistas, especialmente, pelo seu elevado grau de falibilidade.

Dado o exposto, deve-se compreender o reconhecimento de pessoas como o meio de prova pelo qual a vítima ou uma testemunha ocular dos fatos realiza o reconhecimento de outra como o autor da infração penal, sendo que, o processo penal brasileiro adota como método do reconhecimento a forma simultânea, através da qual os possíveis suspeitos do fato delituoso são apresentados ao mesmo tempo ao reconhecedor, o que acaba lhe tornando um método sugestivo e perigoso.

Pela observação dos aspectos e casos analisados, pode-se constatar que o reconhecimento de pessoas, por vezes, pode representar um alto risco à liberdade do indivíduo, passível de gerar sérias injustiças criminais. 
Levando-se em consideração esses aspectos, é-se levado a acreditar que o reconhecimento de pessoas não pode ser considerado uma prova plenamente confiável a embasar um decreto condenatório, pois, possui diversos problemas que o cercam e fazem com que seja um meio de prova frágil, com grande chance de falibilidade, dentre os quais destacam-se a forma com que é conduzido, as falsas memórias e os falsos reconhecimentos.

Dessa forma, conclui-se que o reconhecimento de pessoas não é uma ferramenta comprobatória segura de autoria delitiva, mostrando-se necessária uma reforma legislativa que traga maior segurança ao referido procedimento, pois, conforme demonstrado, a memória humana está sujeita às falsas memórias, bem como à possíveis distorções dos sentidos decorrentes de eventos traumáticos, emoções, esquemas rígidos de pensamento, pensamentos automáticos, preconceitos, e outras situações que podem comprometer a confiabilidade do reconhecimento de pessoas.

\section{REFERÊNCIAS}

AVENA, Norberto Cláudio Pâncaro. Processo penal. 9. ed. São Paulo: Método, 2017.

BARROSO, Luís Roberto. Curso de direito constitucional contemporâneo. 7. ed. São Paulo: Saraiva Educação, 2018.

BONFIM, Edilson Mougenot. Curso de processo penal. 13. ed. São Paulo: Saraiva Educação, 2019.

BRASIL. [Constituição (1988)]. Constituição da República Federativa do Brasil. Disponível em: <http://www.planalto.gov.br/ccivil 03/constituicao/constituicao.htm>. Acesso em: 02 abr. 2020.

BRASIL. [Código de Processo Penal (1941)]. Decreto-Lei n 3.689, de 03 de outubro de 1941. Código de Processo Penal. Disponível em:

<http://www.planalto.gov.br/ccivil 03/decreto-lei/del3689compilado.htm>. Acesso em: 02 abr. 2020.

BRASIL. Poder Judiciário do Estado de Minas Gerais (5a Vara da Fazenda Pública e Autarquias da Comarca de Belo Horizonte). Processo n. 5054558-

63.2016.8.13.0024. Autor: Eugenio Fiuza de Queiroz. Réu: Estado de Minas Gerais. Juiz: Rogerio Santos Araujo Abreu. Belo Horizonte, 09 de outubro de 2019.

Disponível em: 
<https://pje.tjmg.jus.br/pje/ConsultaPublica/DetalheProcessoConsultaPublica/docum entoSemLoginHTML.seam?ca=28e91d5184f6abd51e2b7d828c0e1612e527a191d77 a670ee8b56420e881feb83c4bb3eb346e7d76dd4e70e71862364490047e6a1e2dcf75 \&idProcessoDoc=87387007>. Acesso em: 18 jun. 2020.

BRITO, Alexis Couto de; FABRETTI, Humberto Barrionuevo; LIMA, Marco Antônio Ferreira. Processo penal brasileiro. 4. ed. São Paulo: Atlas, 2019.

CAPEZ, Fernando. Curso de processo penal. 26. ed. São Paulo: Saraiva Educação, 2019.

DALAPOLA, Kaique. 'Vamos fazer uma festona', diz mãe após Justiça dar liberdade a jovem. R7.com, São Paulo, 30 jul. 2019. Disponível em:

$<$ https://noticias.r7.com/sao-paulo/vamos-fazer-uma-festona-diz-mae-apos-justicadar-liberdade-a-jovem-30072019>. Acesso em: 18 jun. 2020.

DEMERCIAN, Pedro Henrique; MALULY, Jorge Assaf. Curso de processo penal. 9. ed. Rio de Janeiro: Forense, 2014.

FIORELLI, José Osmir; MANGINI, Rosana Cathya Ragazzoni. Psicologia jurídica. 8. ed. rev., atual. e ampl. São Paulo: Atlas, 2017.

LIMA, Renato Brasileiro de. Manual de processo penal. 7. ed. Salvador: Juspodivm, 2019.

LOPES JUNIOR, Aury. Direito processual penal. 16. ed. São Paulo: Saraiva Educação, 2019.

MACHADO, Antônio Alberto. Curso de processo penal. 6. Ed. São Paulo: Atlas, 2014.

MARCÃO, Renato. Curso de processo penal. 4. ed. São Paulo: Saraiva Educação, 2018.

MENDRONI, Marcelo Batlouni. Provas no processo penal: estudo sobre a valoração das provas penais. 2. ed. São Paulo: Atlas, 2015.

MESSIAS, Irajá Pereira. Da prova penal. 2. ed. Campinas: Bookseller, 2001.

NUCCI, Guilherme de Souza. Manual de processo penal. Rio de Janeiro: Forense, 2020.

$\mathrm{NUCCl}$, Guilherme de Souza. Princípios constitucionais penais e processuais penais. 4. ed. Rio de Janeiro: Forense, 2015.

PACELLI, Eugênio. Curso de processo penal. 24. ed. São Paulo: Atlas, 2020. 
PAVANELLI, Lucas. Artista confundido com Maníaco do Anchieta será indenizado. R7.com, Minas Gerais, 11 out. 2019. Disponível em: <https://noticias.r7.com/minasgerais/artista-confundido-com-maniaco-do-anchieta-sera-indenizado-11102019>. Acesso em: 18 jun. 2020.

PAVANELLI, Lucas; RAMOS, Gisele. Confundido com maníaco, idoso espera indenização há 5 anos. R7.com, Minas Gerais, 22 ago. 2019. Disponível em: $<$ https://noticias.r7.com/minas-gerais/confundido-com-maniaco-idoso-esperaindenizacao-ha-5-anos-22082019>. Acesso em: 18 jun. 2020.

RANGEL, Paulo. Direito processual penal. 23. ed. São Paulo: Atlas, 2015.

RIZZO, Marcel. Novo julgamento inocenta homem preso no Ceará durante 5 anos por estupro. Folha de São Paulo, Fortaleza, 05 ago. 2019. Disponível em:

<https://www1.folha.uol.com.br/cotidiano/2019/08/novo-julgamento-inocenta-homempreso-no-ceara-durante-5-anos-por-estupro.shtml>. Acesso em: 18 jun. 2020.

ROCHA, Francisco de Assis do Rêgo Monteiro. Curso de direito processual penal. Rio de Janeiro: Forense, 1999.

SALVIANO, Murilo. DJ preso injustamente por latrocínio no Rio conta como foi passar o aniversário na cadeia. G1, Rio de Janeiro, 25 jan. 2019. Disponível em: <https://g1.globo.com/rj/rio-de-janeiro/noticia/2019/01/25/dj-preso-injustamente-porlatrocinio-no-rio-conta-como-foi-passar-o-aniversario-na-cadeia.ghtml>. Acesso em: 18 jun. 2020.

TÁVORA, Nestor; ALENCAR, Rosmar Rodrigues. Curso de direito processual penal. 11. ed. Salvador: Juspodivm, 2016.

Artigo recebido em: 19/06/2020

Artigo aceito em: 04/08/2020

Artigo publicado em: 12/08/2020 